This PDF is a selection from an out-of-print volume from the National Bureau of Economic Research

Volume Title: The Rate and Direction of Inventive Activity: Economic and Social Factors

Volume Author/Editor: Universities-National Bureau Committee for Economic Research, Committee on Economic Growth of the Social Science Research Council

Volume Publisher: Princeton University Press

Volume ISBN: 0-87014-304-2

Volume URL: http://www.nber.org/books/univ62-1

Publication Date: 1962

Chapter Title: Intellect and Motive in Scientific Inventors: Implications for Supply

Chapter Author: Donald W. MacKinnon

Chapter URL: http://www.nber.org/chapters/c2132

Chapter pages in book: (p. $361-384)$ 


\title{
Intellect and Motive in Scientific Inventors: Implications for Supply
}

\author{
DONALD W. MACKINNON \\ INSTITUTE OF PERSONALITY ASSESSMENT AND RESEARCH \\ UNIVERSITY OF CALIFORNIA, BERKELEY
}

Two major types of inventors have been noted: inventors working as researchers in an industrial organization, sometimes referred to as captive inventors, and inventors working on their own as individuals, sometimes called independent inventors. Inventors of the second type may be self-employed, devoting all their working hours to invention, or they may be engaged in full-time employment having nothing to do with inventing. The latter, despite the fact that they devote only their spare time, mainly weekends and evenings, to inventive activity, are nevertheless often so absorbed in it that being an inventor becomes for them their major professional identity. Still other independent inventors engage in inventive activity only as a hobby.

Report is here made on a group of inventors employed in industrial research and a group of individual inventors whose inventive activity varies from being a hobby to being serious part-time self-employment.' The data on these two groups of inventors take on added significance since it is possible to relate them to data gathered in the study of other creative groups: research scientists, mathematicians, architects, and writers. ${ }^{2}$

The design of the over-all research provides for the study of creative persons in these several fields so that eventually something can be said about what characterizes creativity generally, regardless of the special field in which it may manifest itself, and a delineation made of the characteristics of the creative worker and his mode of work in each of the areas studied.

\footnotetext{
${ }^{1}$ In preparing this report and in testing the independent inventors I have been ably assisted by Wallace B. Hall, who in addition has been responsible for the preparation of the statistical data here reported.

${ }^{2}$ These studies are part of a larger investigation of creative work and creative workers in the arts, sciences, and professions being carried out in the Institute of Personality Assessment and Research at the University of California, Berkeley, supported in part by funds granted by the Carnegie Corporation of New York. The statements made and views expressed here are, however, solely the responsibility of the author.
} 
With the exception of the independent inventors, who participated only in a six-hour program of psychological testing, the creative groups were intensively studied by the assessment method which was developed in the Office of Strategic Services during World War II for the purpose of studying highly effective persons. The method as employed in the researches here reported involves bringing the individuals to be studied together during a weekend in an assessment center where they meet with each other and with a staff of psychologists, participate in a series of experiments, take tests of personality traits, attitudes, interests, and values, and are interviewed concerning their life histories and their professional careers.

In a study of the creativity of 45 research scientists employed in three industrial firms and engaged in research and development in guided missiles and electronics, it was discovered that 27 were inventors, 18 noninventors. ${ }^{3}$ The criteria for inventor were that the research scientist be a patentee, had applied for a patent, or made a disclosure; criterion for noninventor was that he failed to meet any of the criteria for inventor. Hereafter the two groups will be referred to as research scientist inventors and research scientist noninventors.

The independent inventors for whom data will be reported are 14 adult males engaged in full-time employment unrelated to inventive activity but who devote varying amounts of their free time to such activity and all of whom conceive themselves as inventors as witnessed by their membership in the International Inventors Association. ${ }^{4}$ The other creative groups with whom the inventors will be compared are nationwide, though small samples, of 20 writers (poets, novelists, and essayists), 12 women mathematicians, and 40 architects. ${ }^{5}$

In assessing our several creative groups we have found a characteristic and distinguishing pattern of interests as indicated by scores on

${ }^{3}$ This study of professional research scientists was conducted by Harrison G. Gough and Donald G. Woodworth. I am indebted to them for making their data available and permitting me to examine the characteristics of the two subgroups of inventors and noninventors.

The industrial laboratories in which these 45 research scientists work are those of the Dalmo-Victor Company, San Carlos, California; the Lockheed Corporation Laboratories, Sunnyvale, California ; and Varian Associates, Stanford, California.

'I wish to express my appreciation to those members of the Association who consented to be studied, and especially to Laurence J. Udell, Secretary-Treasurer of the Association, for his invaluable aid in eliciting their participation.

${ }^{5}$ I am indebted to project directors Frank Barron for data on the writers and Ravenna Helson for data on the women mathematicians. I have directed the study of architects with the assistance of the project's co-director, Wallace B. Hall. 
certain scales of the Strong Vocational Interest Blank. ${ }^{6}$ From sample to sample there has been some slight variation, but the general pattern has been for original and creative subjects, as well as for highly effective persons as first reported by Gough, ${ }^{7}$ to show relatively high scores on such scales as artist, psychologist, architect, author-journalist, and specialization level, and relatively low scores on scales such as purchasing agent, office man, banker, farmer, carpenter-and most interestingly-policeman and mortician.

This pattern of interests as revealed on the Strong Vocational Interest Blank can best be interpreted as indicating that more original and creative subjects are generally less interested in matters of small detail or concerned with them primarily for their wider meanings and implications, less concerned with regulation and control, possessed of greater cognitive flexibility, and interested in ideas and in communicating them accurately to others.

Table 1 lists the interest scales of the S.V.I.B. on which the research scientist noninventors, research scientist inventors, and independent inventors earned high ( $\mathrm{A}$, indicated by an asterisk, or $\mathrm{B}+$ ) scores. It is immediately apparent that both the inventors and noninventors of the research scientist group have many more as well as broader

TABLE 1

Mean Scores of A or B+ on Strong Vocational Interest Blank SCALES For THE THREe Groups

\begin{tabular}{|c|c|c|}
\hline $\begin{array}{l}\text { Research Scientists } \\
\text { Noninventors }\end{array}$ & $\begin{array}{l}\text { Research Scientists } \\
\text { Inventors }\end{array}$ & $\begin{array}{l}\text { Independent } \\
\text { Inventors }\end{array}$ \\
\hline $\begin{array}{l}\text { *Psychologist } \\
\text { *Architect } \\
\text { Physician } \\
\text { Mathematician } \\
\text { Engineer } \\
\text { *Chemist } \\
\text { Math and Sci. Teach. } \\
\text { Personnel Director } \\
\text { *Public Administrator } \\
\text { Social Worker } \\
\text { Musician } \\
\text { Senior CPA }\end{array}$ & $\begin{array}{l}\text { *Psychologist } \\
\text { *Architect } \\
\text { Mathematician } \\
\text { *Engineer } \\
{ }^{*} \text { Chemist } \\
\text { Production Mgr. } \\
\text { Math and Sci. Teach. } \\
\text { Public Administrator } \\
\text { Musician } \\
\text { Senior CPA }\end{array}$ & $\begin{array}{l}\text { *Engineer } \\
\text { *Production Mgr. } \\
\text { Farmer } \\
\text { Carpenter }\end{array}$ \\
\hline
\end{tabular}

* Specialization level.

- E. K. Strong, Jr., Manual for Strong Vocational Interest Blanks for Men and Women, Revised Blanks, Palo Alto, Consulting Psychologists Press, 1959.

${ }^{7}$ H. G. Gough, "Some Theoretical Problems in the Construction of Practical Assessment Devices for the Early Identification of High Level Talent," Berkeley, University of California (mimeographed), 1953. 
interests than do the independent inventors, and they are more certain of these interests and almost certainly pursue them with greater energy (as their higher scores on the specialization scale indicate). Actually there is an interesting progression in number of fields of high interest from independent inventors (4), to research scientist inventors (10), to research scientist noninventors (12).

Qualitative differences in the interests of the three groups are also evident. The independent inventors are in their interests clearly oriented toward things rather than people, and though this interest in things also characterizes the research scientists there is in their case an added interest in and orientation toward persons, and this is even more characteristic of the noninventors than of the inventors among them. There is a progression in range of interests from things to people as one moves from independent inventors to research scientist inventors to research scientist noninventors.

Another difference to be noted in the pattern of high interests of the three groups is a predominant interest in details and in concrete physical objects on the part of the independent inventors in contrast to a greater interest in wholes, complex configurations, and the ideational and the abstract on the part of the research scientists and especially those who are noninventors.

These differences in interest patterns of the independent inventors and the research scientists, including both inventors and noninventors, suggest that the two groups should differ also in socioeconomic status, level of education and training, and in occupational level, and indeed they do.

Of the 45 research scientists, 80 per cent come from families of middle or upper middle class status with fathers in skilled, semiprofessional or professional occupations. All but five of the group have had some formal graduate training, and 28 of them have Ph.D.'s in their specialties. Employed as industrial research scientists, they are 100 per cent in professional positions. In age they range from 24 to 54 with a mean age of 35 years. In regard to these several variables, the inventors among the research scientists are not significantly different from the noninventors.

Of the 14 independent inventors, only 64 per cent come from families of middle class or better. Forty-two per cent of their fathers were in skilled trades, only 21 per cent were in professional or semiprofessional occupations. Only three in the group hold a baccalaureate degree, while two completed one year of college. One completed one year 
of high school while another finished two years. Exactly one-half of the group completed four years of high school. As for their type of employment, eleven are in skilled trades, one in semiskilled, one in semiprofessional, and one in professional work. In age they range from 29 to 71 with a mean age of 47 years.

These marked differences between the industrial research scientists and the independent inventors suggest that they must differ also with respect to intelligence. On the Concept Mastery Test (Terman, 1956) ${ }^{8}$ the research scientists' mean score was 118.2 with a standard deviation of 29.4 , the mean score of the independent inventors being 50.8 and the standard deviation, 34.7. Despite this great difference in measured intelligence between the independent inventors and the research scientists as a group, there was no significant difference in the test scores of inventors and noninventors among the research scientists: research scientist noninventors 117.3 , standard deviation 30.9 ; research scientist inventors 118.9, standard deviation 28.2. It is of some interest to compare the performance of our three groups with that of other groups tested by the Terman test. Table 2 presents these data.

It is to be expected that, on a test of verbal intelligence with such a high ceiling, creative writers will surpass all others. But, in view of our concern with the relation of intelligence to inventive activity, it is surprising to discover our sample of independent inventors scoring as a group lower than any other group to whom we have administered

TABLE 2

Mean Scores and Standard Deviations for Various Groups on the CONCEPT Mastery TeSt, Form $T$

\begin{tabular}{lrcc}
\hline \hline \multicolumn{1}{c}{ Group } & Number & Mean & $\begin{array}{c}\text { Standard } \\
\text { Deviation }\end{array}$ \\
\hline Writers & 20 & 156.4 & 21.9 \\
Subjects of Stanford Gifted Study & 1004 & 136.7 & 28.5 \\
Women mathematicians & 41 & 131.7 & 33.8 \\
Graduate students & 125 & 119.2 & 33.0 \\
Research scientists: inventors & 27 & 118.9 & 28.2 \\
Research scientists: noninventors & 18 & 117.3 & 30.9 \\
Creative architects & 40 & 113.15 & 37.7 \\
Undergraduate students & 201 & 101.7 & 33.0 \\
Spouses of gifted subjects & 690 & 95.3 & 42.7 \\
Air Force captains & 344 & 60.1 & 31.7 \\
Independent inventors & 14 & 50.8 & 34.7 \\
\hline
\end{tabular}

${ }^{8}$ L. M. Terman, Concept Mastery Test, Manual, Form T, New York, Psychological Corporation, 1956. 
the Concept Mastery Test. The inventors among the research scientists as well as the noninventors in that sample, on the other hand, earned very respectable scores, scoring at about the level of graduate students.

In view of the marked difference in mean intelligence scores between our two groups of inventors one might well guess that they differ also in the amount of inventive activity engaged in or the success with which they carry on their inventive efforts. Actually, however, the mean number of patents held by the independent inventors is 1.25 while the mean number held by the research scientist inventors is only 0.88 . This difference is, of course, not significant, but at least in terms of this criterion the group of inventors scoring higher on intelligence shows no superiority to the group scoring appreciably lower. It must be noted, however, that proportionately more of the research scientist inventors are patentees (48 per cent), as against 36 per cent of the independent inventors. ${ }^{9}$

There is evidence, too, that the research scientist inventors engage in more inventive activity or at least more often move in the direction of patenting their inventions in so far as they, more often than the independent inventors, make disclosures and apply for patents. An inventive index - a weighted score for inventive activity in which a disclosure is given a weight of 1 , an application a weight of 2 , and a patent granted a weight of 3 -has been computed for each inventor studied, and the mean inventive index calculated for the two samples of inventors. The mean inventive index for research scientist inventors is 10.5 , with a standard deviation of 13.0 ; for independent inventors it is 4.3 with a standard deviation of 8.5 .

If one considers, however, that the research scientist inventors are employed full-time in inventive activity while the independent inventors engage in such activity only in such leisure time as they can make for themselves, and if one remembers further the striking difference

\footnotetext{
${ }^{\theta}$ The general level of inventive activity is low for both groups studied. The mean number of patents held by the research scientist inventors, 0.88 , is almost certainly an underestimation of the inventive activity in this group, and probably is to be explained by the fact that for the most part members of this group have been working on classified research supported by government contracts, in connection with which patent applications are not likely to be made. The mean number of patents held by the independent inventors, 1.25, may well underestimate their inventive activity also, since for the most part members of this group have been handicapped by lack of financial resources. No outstandingly successful inventor was included in the sample of independent inventors, and despite the almost certain underestimation of inventive activity in both samples of inventors there is reason to believe that, indeed, in both groups the level of inventive activity was relatively low.
} 
in measured intelligence between the two groups, it is most surprising that the differences in their inventive activity and inventive accomplishments are not greater.

It is interesting to note in this connection that the inventor who, of all those studied by us, holds the largest number of patents, 11 in all, is not one of the research scientists but an independent inventor with a score of 6.0 on the Concept Mastery Test. This is the second lowest score earned by any of the subjects we have tested. The lowest score earned by any of the research scientist inventors was 72 . If, instead of looking only at the final total score of this most inventive inventor in the two samples, one examines the way in which he earned it, a most interesting finding emerges.

The test is "a measure of ability to deal with abstract ideas at a high level" and consists of two parts: Part I, Synonyms-Antonyms, is essentially a vocabulary test of knowledge; Part II, Analogies, is a test of word knowledge, general information, and reasoning ability. Instructions for the test specify that one should not guess but should instead answer only those items for which the correct response is known. Score for Part $I$ of the test is number right minus number wrong, for Part II number right minus one-half number wrong. Total score is score for Part I plus score for Part II. With this method of scoring it is clear that a subject who guesses when he does not know is apt to be penalized, and will be if he is wrong. The total score consequently does not indicate the total number of correct responses a subject gives, which in the case of our inventive inventor is 87 rather than 6. It would appear then that this individual has a fair amount of correct knowledge which he can record, but also a good deal of wrong information which he does not hesitate to give.

One wonders, then, if this might not be a salient trait of the inventor who succeeds, namely, that he is willing to take a chance, to try anything that might work, even in taking a test of intelligence. But one also wonders whether this might not be more characteristic of inventors who possess less general information, who are relatively less intelligent, and who are in general less well educated-in other words, the independent inventors of the present study.

Table 3 shows the mean total correct score (which ignores and does not penalize for wrong answers) on the Concept Mastery Test for independent inventors and the two groups of research scientists. The relative standing of the three groups re intelligence is in no way changed by this new method of scoring the test. The noninventors and 
TABLE 3

Mean Total Correct Scores and Standard Deviations for Three Groups on the Concept Mastery Test, Form T

\begin{tabular}{lccc}
\hline \multicolumn{1}{c}{ Group } & Number & Mean & $\begin{array}{c}\text { Standard } \\
\text { Deviation }\end{array}$ \\
\hline Research scientists-Noninventors & 18 & 137.9 & 22.7 \\
Research scientists-Inventors & 27 & 139.0 & 24.6 \\
Independent inventors & 14 & 85.2 & 32.2 \\
\hline
\end{tabular}

inventors among the research scientists are not distinguishable in respect of the amount of correct knowledge which they have, but both groups are clearly set apart from and markedly superior to the independent inventors.

The difference in intelligence test performance between both groups of the research scientists and the independent inventors is further indicated in Table 4, which gives for the three groups the ratio of the total number of wrong answers to the total number of answers given on the same test. A ratio of 0 would mean that no errors or wrong guesses

TABLE 4

Ratio of Total Errors to Total Questions Answered on the CONCEPt MAstery Test, Form T, for Three Groups

\begin{tabular}{lccc}
\hline \hline \multicolumn{1}{c}{ Group } & Number & Mean & $\begin{array}{c}\text { Standard } \\
\text { Deviation }\end{array}$ \\
\hline Research scientists-Noninventors & 18 & 0.17 & 0.10 \\
Research scientists-Inventors & 27 & 0.15 & 0.06 \\
Independent inventors & 14 & 0.35 & 0.12 \\
\hline
\end{tabular}

had been made. The research scientists are either quite accurate or quite cautious in taking the test; at least both groups give relatively few false answers. In contrast the independent inventors make proportionately more erroneous responses. It may be noted that the difference in mean ratio between independent inventors and research scientist inventors is significant at the 0.001 level with a $t$ of 5.68 .

With these data we are now in a position to answer the query raised above as to whether the tendency to take a chance, to try anything that might work (as revealed in the analysis of performance on the Concept Mastery Test), is more characteristic of less well endowed and less well educated inventors (the independent inventors) than of inventors more intelligent and better educated (the research scientist 
inventors). The answer can be found in the correlation of the Concept Mastery Test ratio (total errors to total number answered) with the inventive index already described. For the research scientist inventors the correlation is -0.16 , for the independent inventors, +0.49 . The difference is significant beyond the 0.06 level and strongly suggests that the more inventive a research scientist inventor is, the less inclined he is to take chances, i.e., to offer erroneous answers in taking an intelligence test; while the more inventive an independent inventor is, the more disposed he will be-and this indeed to a marked degreeto try anything that might work.

These analyses of the intelligence test performance of independent inventors, in contrast to research scientist inventors, reveal an attitude and set which appear to characterize them very generally. It is, in part, a lack of critical attitude toward themselves, their ideas, and their abilities, which frees and liberates them for actions and responses that more self-critical, inhibited, and conforming individuals could never bring themselves to make. One would expect a person with such an attitude to have a rather good opinion of himself. Such a person would consequently not be embarrassed by failure, the very thought of which would inhibit others. The willingness "to cut and try," so long observed to be characteristic of the inventor in his inventive activity, appears to apply to one type of inventor - the less intellectually gifted and less well educated. It appears to characterize him no less when he is taking an intelligence test than when he is engaged in other activities. Such an attitude toward work can, on a purely statistical basis, increase the probability of a correct response being made or an inventive solution being achieved. In his inventive striving our independent inventor does not penalize himself for trials that do not work, but in the arbitrary scoring of an intelligence test, as we have seen, he is penalized, with the result that his measured intelligence correlates only imperfectly with his effective intelligence in any situation calling for an inventive response.

If the attitude or mental set with which one takes a test of intelligence can have such consequences as have just been reviewed, and if, as would seem to be the case, such sets operate not only in the intelligence testing situation but in work and life situations as well, it is reasonable to suppose that other sets and orientations toward work may also distinguish the inventor from the noninventor as well as one kind of inventor from another.

Gough and Woodworth undertook to discover in their study of 
the 45 research scientists, for whom data are being presented throughout this paper, whatever stylistic differences might exist in their subjects' attitudes and habits and views of themselves as researchers. ${ }^{10}$ To this end, in collaboration with a group of engineers and research scientists, they assembled a list of 56 statements and phrases descriptive of the various ways in which industrial researchers go about their work and perceive themselves. The following selected statements will give some idea of what the complete list is like: (1) pursues details and ramifications of research problems with great thoroughness; (2) likes to play his hunches in research and is guided by his subjective impressions; (3) prefers to work alone-is not a "team" research man; (4) likes to talk out his research ideas and get other people's reactions; (5) somewhat given to bluffing and claims to know more than he does.

The second task was to ask each subject to sort these 56 statements over a 5-step scale of relevance to himself in frequencies of $5,12,22$, 12 , and 5 , ranging from the 5 statements most descriptive of him to the 5 items least applicable to him. The next task was to intercorrelate the sortings made by each of the 45 subjects and then to factor analyze the matrix of intercorrelations. From this matrix eight "personfactors" or types of researchers were extracted.

Subjects having the highest loadings on each of these stylistic factors were identified. The eight stylistic types were then studied in relation to assessment data drawn from other sources to reveal what psychologically characterized each of the types. In the light of this analysis, Gough and Woodworth have described and labeled the eight types of industrial researchers found in their study as follows: ${ }^{11}$

TYPE I: THE ZEALOT. This man is dedicated to research activity; he sees himself as a driving, indefatigable researcher, with exceptional mathematical skills and a lively sense of curiosity. He is seen by others as tolerant, serious-minded, and conscientious, but as not getting along easily with others and as not being able to "fit in" readily with others.

\footnotetext{
${ }^{10} \mathrm{H}$. G. Gough and D. G. Woodworth, "Stylistic Variations among Professional Research Scientists," Journal of Psychology, Vol. 49, pp. 87-98.

${ }^{11}$ It should be noted that the original classification into the type categories is based on self-perceptions and self-definitions, as embodied in the Q-sort phrases. However, the later explication of the type-psychology includes the evaluations and descriptions contributed by assessment observers. The summary statement for each type thus includes (1) a formulation of the key elements from the self-descriptive classificatory Q-sort phrases, and (2) an inductive sketch of the personological components of each type as seen by psychologist observers.
} 
TYPE II: THE INITIATOR. This man reacts quickly to research problems, and begins at once to generate ideas; he is stimulating to others and gives freely of his own time; he sees himself as being relatively free of doctrinaire bias-methodological or substantive-and as being a good "team" man. Observers describe him as ambitious, well-organized, industrious, a good leader, and efficient. They also characterize him as being relatively free of manifest anxiety, worry, and nervousness.

TYPE III: THE DIAGNOSTICIAN. This man sees himself as a good evaluator, able to diagnose strong and weak points in a program quickly and accurately, and as having a knack for improvising quick solutions in research trouble spots. He does not have strong methodological preferences and biases, and tends not to be harsh or disparaging towards others' mistakes and errors. Observers see him as forceful and self-assured in manner, and as unselfish and free from self-seeking and narcissistic striving.

TYPE IV: THE SCHOLAR. This man is blessed with an exceptional memory, and with an eye for detail and order. However, he is not a research perfectionist nor an endless seeker for ultimates. He does not hesitate to ask help when blocked in his work, and feels that he can adapt his own thinking to that of others. $\mathrm{He}$ is well-informed in his field, and is not given to bluffing. Observers describe him as conscientious and thorough, and as very dependable, but as lacking confidence and decisiveness of judgment.

TYPE V: THE ARTIFICER. This man gives freely of his own time, and enjoys talking shop with other researchers. He is aware of his own limitations and does not attempt what he cannot do. He sees himself as having a special facility for taking inchoate or poorly formed ideas of others and fashioning them into workable and significant programs. Observers see him as honest and direct, getting along well with others, and as usually observant and perceptive and responsive to nuances and subtleties in others' behavior.

TYPE VI: THE ESTHETICIAN. This man favors analytical over other modes of thinking, and prefers research problems which lend themselves to elegant and formal solutions. His interests are far-ranging, and he tends to become impatient if progress is slow or if emphasis must be put upon orderliness and systematic detail. His own view of experience is primarily an esthetic one. Observers 
see him as clever and spontaneous, but as undependable and immature, somewhat lacking in patience and industry and indifferent about duties and obligations.

TYPE VII: THE METHODOLOGIST. This man is vitally interested in methodological issues, and in problems of mathematical analysis and conceptualization. He is open about his own research plans and enjoys talking about them with others. He has little competitive spirit and tends to take a tolerant view of research differences between himself and others. Observers characterize him as a considerate, charitable person, free from undue ambition; at the same time they report a certain moodiness and an occasional tendency toward complicated and difficult behavior.

TYPE VIII : THE INDEPENDENT. This man eschews "team" efforts, and dislikes and avoids administrative details connected with research work. He is not a driving, energetic research man, although he does have a lively sense of intellectual curiosity. He prefers to think in reference to physical and structural models rather than in analytical and mathematical ways. Observers describe him as active and robust in manner and hard-headed and forthright in judgment. He appears relatively free from worry and self-doubt, but inclined to behave impolitely or abruptly. ${ }^{12}$

It is of some interest to inquire concerning the frequency with which each of the eight types occurred among the independent inventors as well as among the inventors and noninventors of the research scientist group. The answer to this question can be given (cf. Table 5),

TABLE 5

Percentage of the Eight Stylistic Types of Research Scientists among Research Scientist-Noninventors, Research SCIENTISTINVENTORS, AND INDEPENDENT INVENTORS

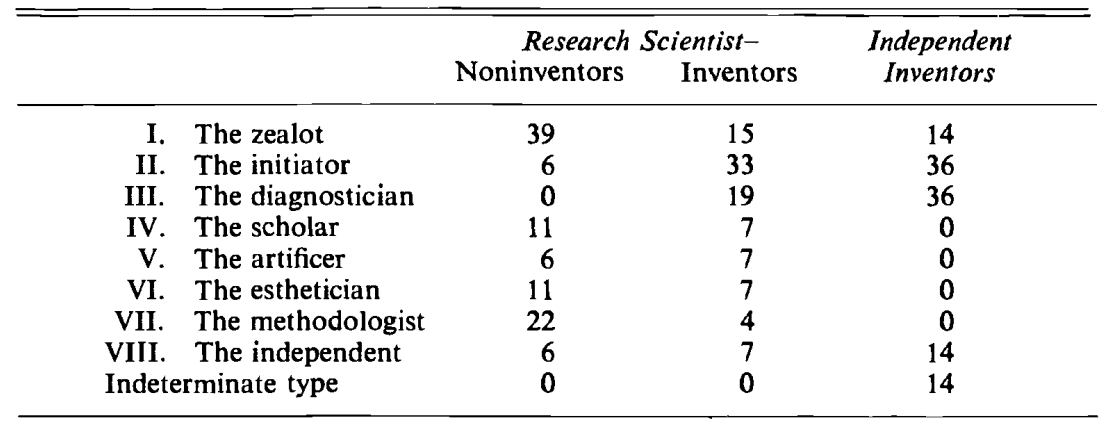

${ }^{12}$ Gough and Woodward, op. cit., pp. 93-94. 
since each of the independent inventors of the present study also sorted the fifty-six statements to describe himself.

In determining the stylistic type for each subject, his own sorting of the fifty-six items was correlated with the sorting for each of the eight types. If an individual's sorting failed to correlate 0.50 with any of the sortings for the eight types he was judged to represent none of them; his own stylistic type was indeterminate with respect to the eight types established in the Gough and Woodworth study. If an individual's sorting correlated 0.50 or better with the sorting for more than one type he was judged to represent that type with which he showed the highest correlation. In cases where an individual's highest correlation was the same ( 0.50 or better) for more than one type he was judged to represent them equally. Thus the percentage of types for the three samples does not always sum to $100 .{ }^{13}$

Among research scientist noninventors the zealot occurs most often, followed by the methodologist, then, with tied frequencies, the scholar and the esthetician. The initiator, artificer, and independent appear infrequently, each accounting for 6 per cent of the group, while the diagnostician never once appears in this subsample.

The picture which one thus gets of the research scientist who is not interested in inventing is that he tends to be dedicated to scientific goals, mathematically skilled, and interested in methodological problems (zealot and methodologist). The same traits, though perhaps less highly developed, doubtless characterize the next most frequently occurring types-the scholar and the esthetician.

The low frequencies with which the initiator, the artificer, and the diagnostician occur suggest that noninventors will not often appear in the guise of the active, outward-going trouble shooter, the man interested in things and in action, and the team man generous of his time with others.

The academician, the intellectual interested in ideas, in elegant mathematical solutions, in methodological niceties-in short, the research scientist who would probably be happier in an academic post rather than in industry - this is the picture which one gets of the industrial research scientist who is not engaged in invention.

${ }^{13}$ If, instead of applying this criterion for type, each independent inventor is assigned to that type with which he correlates most highly (even though less than 0.50 ) the indeterminates turn out to be either initiator or diagnostician. The distributions then become for the independent inventors: the zealot, 14 per cent; the initiator, 43 per cent; the diagnostician, 43 per cent; and the independent, 14 per cent, with the remaining five types having a frequency of 0 per cent. 
The picture obtained earlier from the profile of the Strong Vocational Interest Blank of the independent inventors as persons more oriented to things than to ideas and to people is reconfirmed by the frequency with which the stylistic types are found among them. They are the initiators, the men of action "free from doctrinaire bias," whether methodological or theoretical. They are the diagnosticians, the trouble shooters. Some of them will work with considerable zeal just as some of them will work with considerable independence, but one does not find among them scholars, estheticians, or methodologists. One might have expected to find artificers among them but one does not, quite possibly because the type isolated by Gough and Woodworth represents a very high level research designer and apparatus man and because the artificer type as defined is too much given to working and researching with others while independence appears to be much more emphasized among the lone and individual inventors.

As one might expect, the frequencies with which the several stylistic types occur among the research scientist inventors, in general, fall between the frequencies with which they occur among the other two subgroups. As with the independent inventors, the most frequently occurring types are initiator and diagnostician. Zealots occur with about the same frequency as they do among the independent inventors, though the frequency of the independent type approximates more nearly that with which it occurs among the noninventors.

Especially to be noted is the virtual absence of the methodologist among inventors of both types. Again the inventor appears as one intolerant of methodological issues which, if accepted, would force him to proceed along certain prescribed channels. If there is any method to which he is committed, it is the one that provides him with the maximum freedom for action; for the research scientist inventor this may be in large measure "trial and error" guided by some theoretical considerations, and for the independent inventor it may be predominantly "cut and try" guided by more practical considerations.

The differences between independent inventors, research scientist inventors, and research scientist noninventors with respect to the stylistic variations which they reveal in their approaches and attitudes toward their work suggest that they may also differ in the values they hold. Their differing patterns of interests as revealed on the Strong Vocational Interest Blank show that indeed they do.

In an earlier report it was shown that creative individuals have a 
pattern of values different from less creative persons. ${ }^{14}$ On the AllportVernon-Lindzey Study of Values designed to measure in the individual the relative strength of the six values of men as described by Eduard Spranger-the theoretical, the economic, the aesthetic, the social, the political, and the religious-creative architects, research scientists, and mathematicians show a high elevation on two values: the theoretical and the aesthetic. ${ }^{15}$ As Figure 1 shows, the highest mean value for research scientists is the theoretical followed by the aesthetic; for architects, the aesthetic value is highest with the theoretical value in second place; while for creative mathematicians, the two values are well above average and approximately equally high.

It is not surprising that the theoretical value is highest for the research scientists, or that the aesthetic value is highest for architects. It had not been anticipated, however, that the two highest values for

FIGURE 1

Profiles of Values for Architects, Research Scientists, and Women Mathematicians on the Allport-Vernon-Lindzey Study of Values

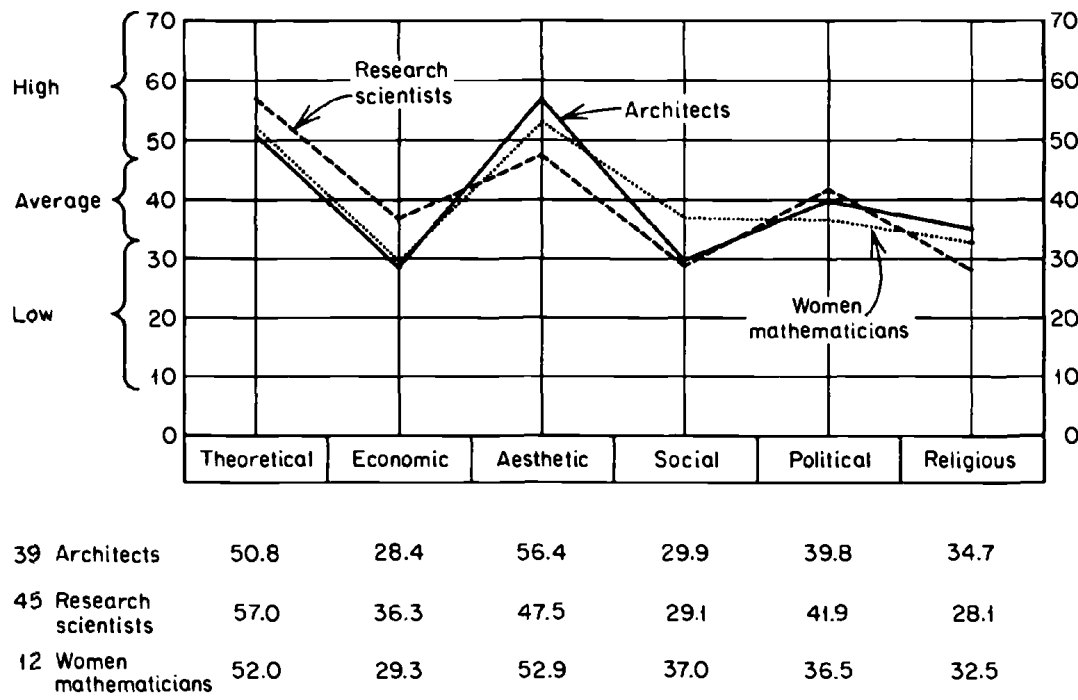

14 D. W. MacKinnon, "Identifying and Developing Creativity," in Selection and Educational Differentiation, T. R. McConnell, Editor, Berkeley, Center for the Study of Higher Education, 1960.

${ }^{15} \mathrm{G}$. W. Allport, P. E. Vernon, and G. Lindzey, Study of Values: Manual of Directions, (rev. ed.), Boston, Houghton Mifflin, 1951. 
architects, research scientists, and mathematicians would be the theoretical and the aesthetic or that they would be of so nearly the same strength in each group, for the developers of this test had described the aesthetic attitude as diametrically opposed to the theoretical. The theoretical man is usually thought of as having a cognitive orientation seeking primarily to observe and to reason, whereas the aesthetic man is described as one who judges all experience from the standpoint of fitness, grace, and symmetry. It may be that for most persons there is some conflict between theoretical and aesthetic values. If so, it would appear that the creative individual has the capacity to tolerate the tension created in him by opposing strong values, and in his life and work effects some reconciliation of them.

The profile of values for the research scientists as shown in Figure 1 is, in Figure 2, redrawn for the two subgroups of research scientists discussed throughout this paper-inventors and noninventors. Figure 2 also shows the profile of values for the independent inventors. For each of the subgroups the theoretical is the highest mean value, but it should be noted that while this value falls in the high range for the

FIGURE 2

Profiles of Values for Independent Inventors, Research Scientist-Inventors, and Research Scientists-Noninventors on the Allport-Vernon-Lindzey Study of Values

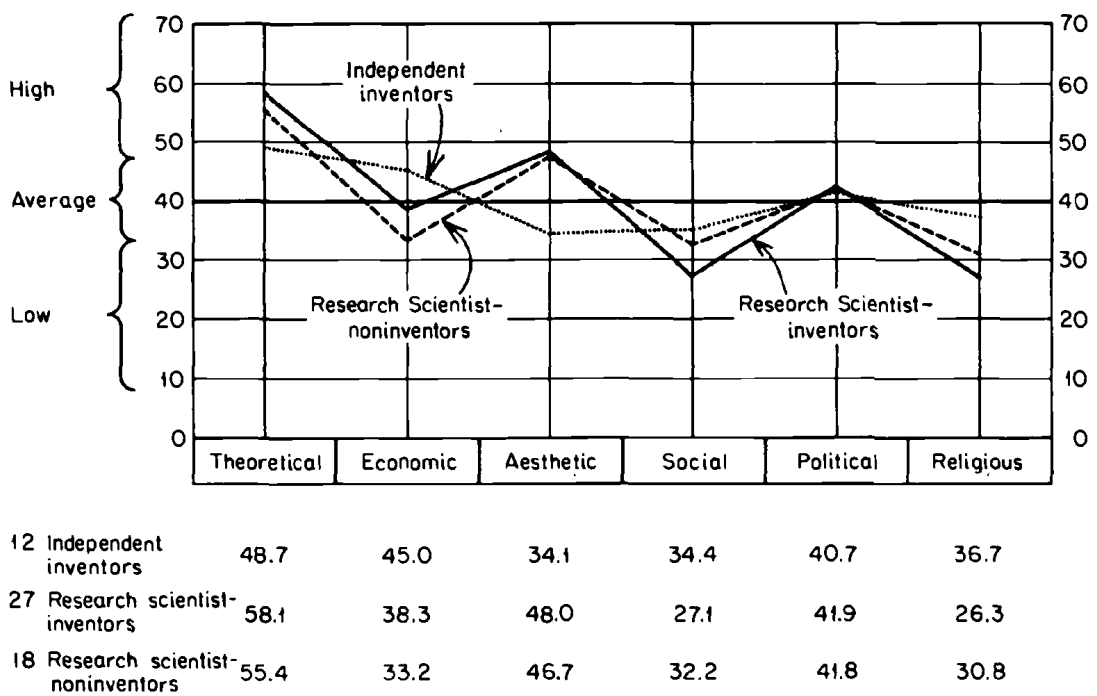


two subgroups of research scientists, it is of only average magnitude for our sample of independent inventors.

The differences are even more striking with regard to the aesthetic value. While this is the second highest value for the research scientists, inventors as well as noninventors, it is the lowest of all values for the independent inventors, whose second highest value is economic rather than aesthetic. It is of interest to note, also, that the independent inventors score higher than the other two groups on social and religious values, while there is no difference among the three groups with regard to political values.

The failure of the independent inventors' profile of mean values to show high peaks on both theoretical and aesthetic values, which all our highly creative groups have shown, suggests that in general the creativity of our independent inventors may be less and will certainly be of a different type and form or both, from that of the other groups. Specifically, one might hazard the opinion that the independent inventors are less impressed by elegant solutions of intricate and abstract theoretical problems and relatively unmotivated to deal with them. Rather it is the functional and utilitarian aspects of problems which intrigue them. It is the "desire to improve" 16 already existing physical inventions, to make them more efficient and more useful that looms large in the motivational structure of the independent inventors. The economic drive, argued by Bennett to be the primary motive for inventive activity, ${ }^{17}$ plays a more salient role in the case of these inventors who, in general, come from families of relatively low socioeconomic status and have been unable to improve their own position. But even in this group it is not the economic value which is highest; it is the theoretical value, though less highly developed than in the other creative samples we have studied.

The implications of the researches here reported for questions concerning the supply of inventors can be discussed in only the most restricted and tentative fashion. It must be emphasized that the samples for which data have been presented are small, and individual differences within each sample are rather large as the reported standard deviations for the various group means indicate. Thus the differences between the several groups discussed are far from definitive. They are

${ }^{16}$ The second most frequently mentioned motive for inventing of the respondents in Rossman's study of inventors (J. Rossman, The Psychology of the Inventor: A Study of the Patentee, Washington, D.C., The Inventors Publishing Co., 1931).

1; W. B. Bennett, The American Patent System: An Economic Interpretation, Baton Rouge, Louisiana State University Press, 1943. 
at best suggestive, and require further study in larger samples. They do, however, possess considerable psychological verisimilitude and for this reason have been judged worthy of discussion.

It must be emphasized that of the three classes of inventions and inventors often described we have so far sampled only two. None of the subjects studied by us have produced basic, extensive, laborproducing and factor-producing inventions. We have caught in our assessment net none of the truly great or outstanding inventors, either captive or independent. Our subjects, instead, have been drawn from the other two classes of inventors: on the one hand, those who have produced developmental, intensive, improving, laborsaving and factor-displacing inventions and, on the other hand, producers of minor inventions which result in the production of gadgets and the improvement of already existing devices.

To what extent the traits and attributes found to characterize the inventors in the present study would be found in basic inventors we cannot say. What is rather striking in our data are the clear-cut differences between our research scientist inventors and our sample of independent inventors. Whether these differences would be so sharp had our sample of independent inventors been a larger and more representative sample of the population we cannot say with certainty. My guess is that our sample underrepresents the more intelligent, better educated, more successful, and more affluent independent inventors. The small measure of success which our independent inventors had achieved both in their personal lives and in their inventive activity may well have motivated them to volunteer for study in the hope and expectation that participation in the research would in some way increase their own effectiveness. A wider and more adequate sampling of independent inventors would almost certainly have yielded still other types. And the most plausible assumption to be made about those who produce basic inventions is that, if studied, they would reveal still other types of inventors.

Rather than supporting the notion that all inventors are of a single type, our data and the implications to be drawn from them point to the existence of a multiplicity of inventive types. If this is so, one can be somewhat more optimistic about the future supply of inventors than are those observers who have concluded, erroneously in my judgment, that there is only one type of inventor, and he is to be found today almost entirely in large industrial laboratories. 


\section{COMMENT}

Thomas S. Kunn, University of California, Berkeley

Before discussing MacKinnon's paper, I am compelled to a confession. Examining the names and professional qualifications of the other participants in this conference, I doubt my suitability for the role I have been asked to play. Almost certainly I am the only member of the group who has never taken a course in either economics or psychology; very probably I am among the few who have never computed a correlation coefficient or who are forced, while reading over the conference proceedings, to pause in temporary puzzlement every time they encounter a phrase like "marginal utility." In this company, in short, I am a rank outsider. That isolation indicates no lack'of interest in the problems under discussion. On the contrary, at least three of my recurrent roles-as ex-physicist, as practicing historian of science, and as interested citizen-repeatedly confront me with several of the central problems of this conference and often in a most acute form. But the nature of my professional background and concerns does mean that I approach the problems of this conference from a viewpoint very different from that of most other participants. That difference will certainly be reflected in my comments, and under the circumstances, it seems appropriate to make the sources of my viewpoint clear at the very start.

Let me turn now to the illuminating paper contributed to this conference by my Berkeley colleague, Donald MacKinnon. (It is one of the jronies of academic life that I should first meet him at a conference 2,000 miles from home.) That paper attempts to discover, from a variety of psychological tests, the distinctive research styles and personalities of three selected groups: research scientists who are not inventors, research scientists who are inventors, and independent inventors. The result is an investigation that I find particularly interesting, for experience as a historian has long since convinced me that the scientist and the inventor are often profoundly different types and that they characteristically flourish under rather different cultural and social circumstances. Evidence on this point is therefore what 1 particularly sought in MacKinnon's investigation, and I am delighted to report that it can be found there in a particularly striking form. But to isolate that evidence and to see its force, we must first examine those aspects of the investigation that would make it particularly easy for a hostile 
critic to dismiss the whole. Because design weakness is inevitable in any exploratory study, I shall not elaborate negative criticism. But it cannot be avoided entirely, because the most dubious aspects of the sampling procedures employed provide essential background for what seems to me the single most striking point that emerges from the research.

Look first at the two groups that MacKinnon has investigated most thoroughly. They are research scientist noninventors and research scientist inventors. To isolate them for investigation MacKinnon has split into two parts a single group of industrial scientists who were initially selected as a homogeneous sample for another study. ${ }^{1}$ Those members of the initially homogeneous group who possessed at least one patent, patent application, or disclosure have been labeled "inventors"; the remainder of the group are "noninventors." It then turns out that only 48 per cent of the inventors are patentees and that the average number of patents per inventor is 0.88 .

But can we be sure, except in the obvious numerical sense, that we are really dealing with two distinct groups? In industrial research all sorts of accidents may help to determine who gets his name on a patent application or disclosure, particularly if the invention derives from a group project. In addition, as many of the contributors to this conference have emphasized, policy about what to patent and what to keep secret varies immensely in different industrial situations. One may well suspect, therefore, that if there is an inventor type, many of its exemplars will be found among MacKinnon's "noninventors," while many of his "inventors" may not be of the inventor type at all. It is even conceivable that, as industrial scientists, his whole group should be labeled "inventors." Comparison with a sample drawn from university scientists would at least have lent his study more authority. These considerations do not suggest that MacKinnon's segregation of inventors from noninventors must be without significance, but they do raise questions. It can, for example, surprise no one that on almost all the tests the research scientist inventors and the research scientist noninventors show almost identical scores. Only a man trained in the subtlest forms of statistical analysis will feel any assurance that he can tell the two groups apart. But can we conclude anything from this as to the similarity of research scientist inventors and noninventors?

${ }^{1}$ H. G. Gough and D. G. Woodworth, "Stylistic Variations among Professional Research Scientists," Journal of Psychology, XLIX, 1960, pp. 87-98. 
MacKinnon's third sample, the fourteen independent inventors, presents even more profound problems. Who are these people? They have in common their membership in the International Inventors Association, and they share a willingness to volunteer for psychological study. In addition, they are united by the fact that for them invention is only an avocation. Certainly they see themselves as inventors, but it is not clear that we should accept their image. Only 36 per cent of the group possesses a patent and the average number of patents per individual, while higher than that for the research scientist inventors, is only 1.25 per cent. Furthermore, these men are described as relatively little educated and as relatively unsuccessful, both personally and inventively. It is, therefore, not surprising to find that their test results are almost always very different from those of the other two groups. But there seems little reason to suppose that these quite striking differences have much of anything to do with their being "independent inventors." That could be the source of the differences but it surely need not be. Perhaps, for example, they are simply less privileged people.

Under these circumstances there is only one sort of result that participants in this conference should feel forced to accept as fully relevant to the problems that concern them. The similarity between MacKinnon's first two groups and the marked differences between these two and his third need not illuminate those problems. But what would necessarily be both illuminating and convincing would be a test result that displayed marked differences between MacKinnon's first group, the research scientist noninventors, and his second, the research scientist inventors. This discrimination would be even more striking if the same test showed a marked similarity between the two superficially different groups of inventors.

Now MacKinnon does get just such a result, though it is somewhat hidden by his method of presentation. It is contained in his Table 5 which I shall here somewhat simplify and rearrange. In doing so, let me dismiss for the moment-as possible statistical artifacts or as what, in my earlier career as a physicist, I called "dirt"-those entries which contain only one or two individuals. Simultaneously let me regroup the four remaining stylistic types, the ones that contain an obviously significant proportion of the members of at least one of the samples. Immediately a surprising result begins to emerge. Fully 61 per cent of MacKinnon's noninventors are to be found in the combined group representing research styles I and VII, though less than 
20 per cent of either of the inventor groups falls there. On the other hand, if research styles II and III are grouped together, they are found to contain only 6 per cent of the noninventors but 52 per cent of the research scientist inventors. and 72 per cent of the independent inventors. These are the results summarized below in tabular form.

\begin{tabular}{crcc} 
Research Styles & $\begin{array}{c}\text { Research Scientist- } \\
\text { Noninventors } \\
\text { (per cent) }\end{array}$ & $\begin{array}{c}\text { Independent } \\
\text { Inventors } \\
\text { (per cent) }\end{array}$ \\
\hline I and VII & 61 & 19 & 14 \\
II and III & 6 & 52 & 72
\end{tabular}

The summary displays just the sort of result I have suggested that we cannot afford to ignore. The two groups of research scientists, which elsewhere for obvious reasons, have looked very nearly identical, are here sharply distinguished. Simultaneously, the two groups of inventors, which have elsewhere and again for obvious reasons, looked very different, here show marked similarity. This finding may well point to a profoundly significant mode of discrimination. I, therefore, hope that MacKinnon and his colleagues will pursue it further, both with the data already at hand (there is vastly more of it than his paper shows) and with more refined tools of investigation. For example, a restudy of the Q-sort deck used in the investigation to determine which items are particularly responsible for the differentiations above should permit the design of a still more decisive testing tool. ${ }^{2}$

Discussion of what will emerge from this additional investigation should await the results of the research itself. The thumbnail epitomes of the eight stylistic types provided by MacKinnon are too brief to be more than suggestive. Yet they are suggestive, and I cannot quite resist concluding with a few speculative words about them. Presumably the commentator has a license that the author of a formal paper does not. Let me exploit it in order tentatively to note three likely differences between stylistic types I and VII, which include the bulk of

\footnotetext{
2 A cursory inspection of the Q-sort deck used by Gough and Woodworth as well as of the results they got with it (ibid., pp. 89-91) suggests, for example, that more attention be given to "unpopular" stylistic characteristics, ones that nobody in a research organization will quite wish to own to. "Has strong research biases" and "enjoys philosophical speculation" were characteristics of this sort in the Gough and Woodworth research. If I read the paper correctly, few scientists gave either of these characteristics high personal relevance, but the inventors rejected the first more strongly than the scientists, and the scientists rejected the second more strongly than the inventors.
} 
MacKinnon's noninventors, and types II and III, which include the majority of his inventors.

Notice first that both types I and VII, unlike types II and III, give evidence of real difficulty in interpersonal relations. That difficulty could be part of a pattern of partial withdrawal from society, resulting concern with greater abstraction, and a concommitant low evaluation of practical and social service problems. Or again, notice, what is probably not at all surprising, that types II and III, the inventors, are both characterized by an unusual quickness of response and by a marked gift for improvisation. (This part of MacKinnon's finding, being drawn from the Q-sort, may refer only to the self-image, not to the actuality. But that would not deprive it of significance.) By contrast, the scientist noninventor is probably slower and perhaps also more self-critical and inhibited. As a historian, I have the impression that there is significant biographical support for this discrimination.

Finally, notice that groups II and III, the inventors, are just the ones whose members declare themselves markedly free from methodological and substantive bias. This finding seems congruent with the inventors' consciousness of uncommon rapidity and skill in improvisation as well as with the fact, noted by Gough and Woodworth, that the members of groups II and III are more prone to philosophical speculations than are the members of groups I and VII, the scientists. ${ }^{3}$ Taken together these clues point clearly to a larger pattern that is at least implicit in Merrill's excellent contribution to this conference, and that I have developed elsewhere from historical sources. ${ }^{4}$ That pattern suggests that the basic scientist, unlike the inventor, requires for his work a deep immersion in a pre-existing tradition. Such a tradition, acquired through professional training, informs him of the unsolved problems confronting his profession and tells him what will be acceptable as solutions to them. Without an immersion in that tradition he could scarcely operate as a scientist at all. The inventor, in contrast, requires little similar immersion. His problems tend to be externally, not professionally, defined and, in addition, his criterion of success is, of necessity, social adoption. Something of this same distinction seems to me dimly visible in MacKinnon's data.

${ }^{3}$ Ibid.

- T. S. Kuhn, "The Essential Tension: Tradition and Innovation in Scientific Research," in The Third (1959) University of Utah Research Conference on the Identification of Creative Scientific Talent, Calvin W. Taylor, editor, University of Utah Press, 1959, pp. $162-177$. 
Perhaps these tentative conclusions will not withstand the results of further investigation. Nevertheless, it is just because it may well permit conclusions of this sort that MacKinnon's paper seems to me so very challenging and so clearly worth pursuing. 